\title{
Mechanical stress up-regulates RANKL expression via the VEGF autocrine pathway in osteoblastic MC3T3-E1 cells
}

\author{
TAKESHI NAKAI ${ }^{1,2}$, YOSHITAKA YOSHIMURA $^{2}$, YOSHIAKI DEYAMA ${ }^{2}$, \\ KUNIAKI SUZUKI $^{2}$ and JUNICHIRO IIDA ${ }^{1}$ \\ Departments of ${ }^{1}$ Orthodontics and ${ }^{2}$ Molecular Cell Pharmacology, Hokkaido University \\ Graduate School of Dental Medicine, Kita-ku, 060-8586 Sapporo, Japan \\ Received October 10, 2008; Accepted December 23, 2008
}

DOI: $10.3892 / \mathrm{mmr} 00000088$

\begin{abstract}
Although it has been reported that vascular endothelial growth factor (VEGF) promotes not only angiogenesis but also osteoclast and osteoblast differentiation, few reports exist regarding VEGF/VEGF receptor (VEGFR) signaling in osteoblasts, which regulate osteoclast differentiation and generate VEGF. This study examined the expression of the bone remodeling factor VEGF-A and its receptors, VEGFR-1 (Flt-1) and VEGFR-2 (Flk-1/KDR), in murine osteoblastic MC3T3-E1 cells with the application of mechanical stress. The protein concentration of VEGF-A in the mechanical stress group increased markedly compared with the control group, while that of macrophage colony-stimulating factor in the mechanical stress group was lower than in the control group. VEGFR-2 mRNA expression was not detected in osteoblastic MC3T3-E1 cells. Mechanical stress up-regulated VEGF-A, VEGFR-1 and the receptor activator of nuclear factor- $\kappa \mathrm{B}$ ligand (RANKL) mRNA expression. In particular, VEGF-A and RANKL mRNA expression increased immediately after mechanical stress. We examined the VEGF/VEGFR system on anti-mouse VEGF neutralizing antibody in osteoblasts with mechanical stress. Neutralizing antibody to VEGF partially inhibited the increase of VEGF-A and RANKL mRNA expression compared with the non-mechanical stress group. VEGFR-1 mRNA expression was completely suppressed to control levels by the neutralizing antibody to VEGF. These findings suggest that mechanical stress up-regulates RANKL expression via the VEGF/VEGFR-1 autocrine pathway in osteoblastic MC3T3-E1 cells, indicating the possibility that, in response to mechanical stress, osteoblasts increase bone resorption by an autocrine up-regulation of VEGF/VEGFR-1 and RANKL expression.
\end{abstract}

Correspondence to: Dr Yoshitaka Yoshimura, Hokkaido University Graduate School of Dental Medicine, Kita 13, Nishi 7, Kita-ku, 060-8586 Sapporo, Japan

E-mail: yoshi@den.hokudai.ac.jp

Key words: mechanical stress, osteoblast, vascular endothelial growth factor, flexercell tension system

\section{Introduction}

Bone remodeling requires bone resorption and formation and is controlled by osteoclasts and osteoblasts. It was reported that macrophage colony-stimulating factor (M-CSF) and receptor activator of nuclear factor- $\mathrm{B}$ ligand (RANKL) are necessary and sufficient for osteoclast differentiation $(1,2)$. However, M-CSF (also known as CSF-1) was instead found to stimulate osteoclast survival (3), and the binding of RANKL to its receptor RANK proved essential for osteoclast differentiation (4). Osteoprotegerin (OPG) is the decoy receptor for RANKL and inhibits RANKL-RANK signaling (5). Osteoblasts express RANKL and OPG, and coordinate osteoclast differentiation and bone resorption $(6,7)$.

Vascular endothelial growth factor (VEGF) is the most important mediator of angiogenesis (8). VEGF-A (a member of the VEGF family), as a substitute for M-CSF, can enhance osteoclastic bone resorption through its VEGF-A receptors (VEGFR) $(9,10)$. VEGF-A is a significant regulator of angiogenesis and hematogenesis $(11,12)$. The tyrosine kinase receptors VEGFR-1 (Flt-1) and VEGFR-2 (Flk-1/KDR) receive VEGF-A $(13,14)$ and are expressed in mature osteoclasts and osteoblasts (15). In vivo, osteoclasts appear concurrently with blood vessel invasion, and capillary angiogenesis and bone matrix resorption are essential for bone remodeling (16). Therefore, bone vascularization by VEGF-A may lead to the recruitment of osteoblasts and osteoclasts for bone matrix remodeling. Previous studies have reported that the differentiation and migration of osteoblasts are supported by VEGFR-1 signaling (17-19).

Mechanical stress is a key regulator of osteoblast and osteoclast activity in bone. Mechanical stress (mechanical stimulus and loading) regulates the activation and differentiation of osteoblasts $(20,21)$, induces RANKL availability (22) and increases VEGF and M-CSF expression (23). It has been indicated that collagenase-3 (matrix metalloproteinase-13; MMP-13) may act as a 'coupling factor', allowing osteoblasts to exert control over osteoclast resorptive activity (24). Mechanical strain up-regulates MMP-13 expression in MC3T3-E1 osteoblastic cells (25).

In the process of bone remodeling caused by orthodontic force, osteoclasts are induced by osteoblasts. Subsequently, the osteoblasts should form new bone and remodel the resorbed area. Consequently, the function of osteoclasts is enhanced by 
mechanical stress in the orthodontic tooth movement. Since osteoblasts express VEGF-A, VEGFR-1 and VEGFR-2, autocrine action by the VEGF/VEGFR system may up-regulate the differentiation and function of osteoclasts. However, few reports exist on how the VEGF/VEGFR system functions and affects the bone remodeling process under mechanical stress. This study aimed to investigate the VEGF/VEGFR system of osteoblasts with mechanical stress using the flexercell tension system.

\section{Materials and methods}

Cell culture. Murine osteoblastic MC3T3-E1 cells (Riken Cell Bank no. RCB1126, Japan) were used. The cells were cultured in aMEM (Invitrogen, MD, USA) supplemented with $10 \%$ heat-inactivated fetal bovine serum, $66.7 \mu \mathrm{g} / \mathrm{ml}$ kanamycinsulfate and $284 \mu \mathrm{M} \mathrm{L}$-ascorbic acid 2-phosphate at $37^{\circ} \mathrm{C}$ in a humidified atmosphere of $95 \%$ air and $5 \% \mathrm{CO}_{2}$ (26). Subsequently, the cells were cultured to subconfluence in $100 \mathrm{~mm}$ standard dishes (Falcon $^{\mathrm{TM}}$, Becton-Dickinson Labware, Franklin Lakes, NJ, USA) and transferred to Bioflex collagen I-coated 6-well plates (Flexcell Corp., Hillsborough, NC, USA) after treatment with $0.25 \%$ trypsin/EDTA (Invitrogen).

Flexcell tension system and cell culture. Mechanical stress was applied to the MC3T3-E1 cells with a Flexercell Strain-Unit (Flexcell Corp.) $(27,28)$. After being transferred to Bioflex collagen I-coated 6-well plates, the cells were cultured overnight and then mechanically stressed at the following time points: $6,12,24$ and $48 \mathrm{~h}$. The experimental regimens used delivered $10 \%$ elongation at 30 cycles $/ \mathrm{min}(0.5 \mathrm{~Hz})$ in a humidified atmosphere of $95 \%$ air and $5 \% \mathrm{CO}_{2}(28)$. The control culture was grown under the same conditions without mechanical stress.

Reverse transcription-polymerase chain reaction. Total RNA was extracted using the TRIzol reagent isolation kit (Invitrogen). cDNA was amplified by Rever TraAce $\alpha$ FSK101/Toyobo, Japan). Reverse transcription-polymerase chain reaction (RT-PCR) analysis was performed as previously described (28). The primers used were: M-CSF, VEGF-A, VEGFR-1, VEGFR-2, RANKL, OPG, alkaline phosphatase (ALP), collagen type I and MMP-13. Primer sequences are shown in Table I. Amplified products were distributed on a $1 \%$ agarose gel attained with ethidium bromide. The same cDNA was amplified using primers specific for glyceraldehyde-3phosphate dehydrogenase (GAPDH) mRNA in order to equalize the amount of total RNA.

Measurement of VEGF and M-CSF concentrations. Cultured medium was collected from MC3T3-E1 cells that had or had not been exposed to mechanical stress. Protein concentrations of VEGF and M-CSF were measured using Enzyme Linked Immunosorbent Assay (Quantikine M mouse VEGF Immunoassay kit, Quantikine M mouse M-CSF Immunoassay kit; R\&D Systems Inc., Minneapolis, MN, USA) according to the manufacturer's instructions.

Neutralizing effect of anti-VEGF antibody. Anti-mouse VEGF neutralizing antibody (rmVEGF) (AF-493-NA; R\&D Systems Inc.) was added to the culture medium $24 \mathrm{~h}$ before the application of the Flexercell Strain Unit. As the maximum dose,
Table I. Primer sequences.

Gene $\quad$ Primer sequence (5'-3')

$\begin{array}{ll}\text { M-CSF } & \text { F: CCCATATTGCGACACCGAA } \\ \text { R: AAGCAGTAACTGAGCAACGGC }\end{array}$

VEGF-A F: GGACCCTGGCTTTACTGC

R: CGGGCTTGGCGATTTAGOPG

Flt-1VEGFR-1 F: GGTGCCCGCTCTTTG

R: TGTCTCAGTGGGGATTGC

Flk-1VEGFR-2 F: CCTGGCTGACCCGATTCC R: TCCCGCTTTGTTGATGGC

RANKL F: TATGATGGAAGGCTCATGGT

R: TGTCCTGAACTTTGAAAGCC

OPG F: GAGGAAGGAAAGGGCCTATG

R: TGGGAATGAAGATCCTCCAG

ALP F: CGGGGACATGCAGTATGA

R: AAAGATGGAGTTGCCCCG

MMP-13 F: CTTCTGGTCTTCTGGCACAC

R: CCCCACCCCATACATCTGAA

Collagen F: ACTCCCCAGAGTTTGGAACTTACTG

type I R: GTCGGAGCAGACGGGAGTTTCTCCT

GAPDH F: CGGAGTCAACGGATTTGGTCGTAT

R: AGCCTTCTCCATGGTGGTGAAGAC

$\mathrm{F}$, forward; R, reverse.

$\sim 500 \mathrm{pg} / \mathrm{ml}$ of rmVEGF was measured in one of the $48-\mathrm{h}$ mechanical stress groups. Antibody $(20 \mathrm{ng} / \mathrm{ml})$ was applied to neutralize $\sim 100 \%$ of rmVEGF bioactivity according to the manufacturer's dose-response curve.

\section{Results}

Effect of mechanical stress on mRNA expression. VEGFR-2 mRNA expression was not detected in the osteoblastic MC3T3-E1 cells (data not shown). VEGF-A and RANKL mRNA expression in the mechanical stress group was significantly increased at all time points compared with the control group. VEGF-A and RANKL mRNA expression resulted in a 2.7- and 3.6-fold increase at $48 \mathrm{~h}$ (Fig. 1A and C). VEGFR-1 and OPG mRNA expression markedly increased at 24 and $48 \mathrm{~h}$, and resulted in a 2.0 -fold increase at $48 \mathrm{~h}$ (Fig. 1B and D). M-CSF and collagen type I mRNA expression remained unchanged by mechanical stress at all time points (Fig. 1E and G). ALP mRNA expression was time-dependently decreased, culminating in a 0.65 -fold decrease at $48 \mathrm{~h}$ (Fig. 1F). MMP-13 mRNA expression resulted in a 1.5 -fold increase at $48 \mathrm{~h}$ only (Fig. 1H).

VEGF and M-CSF protein concentration. VEGF protein secretion significantly increased in the mechanical stress group compared with the control group at all time points (Fig. 2A). 

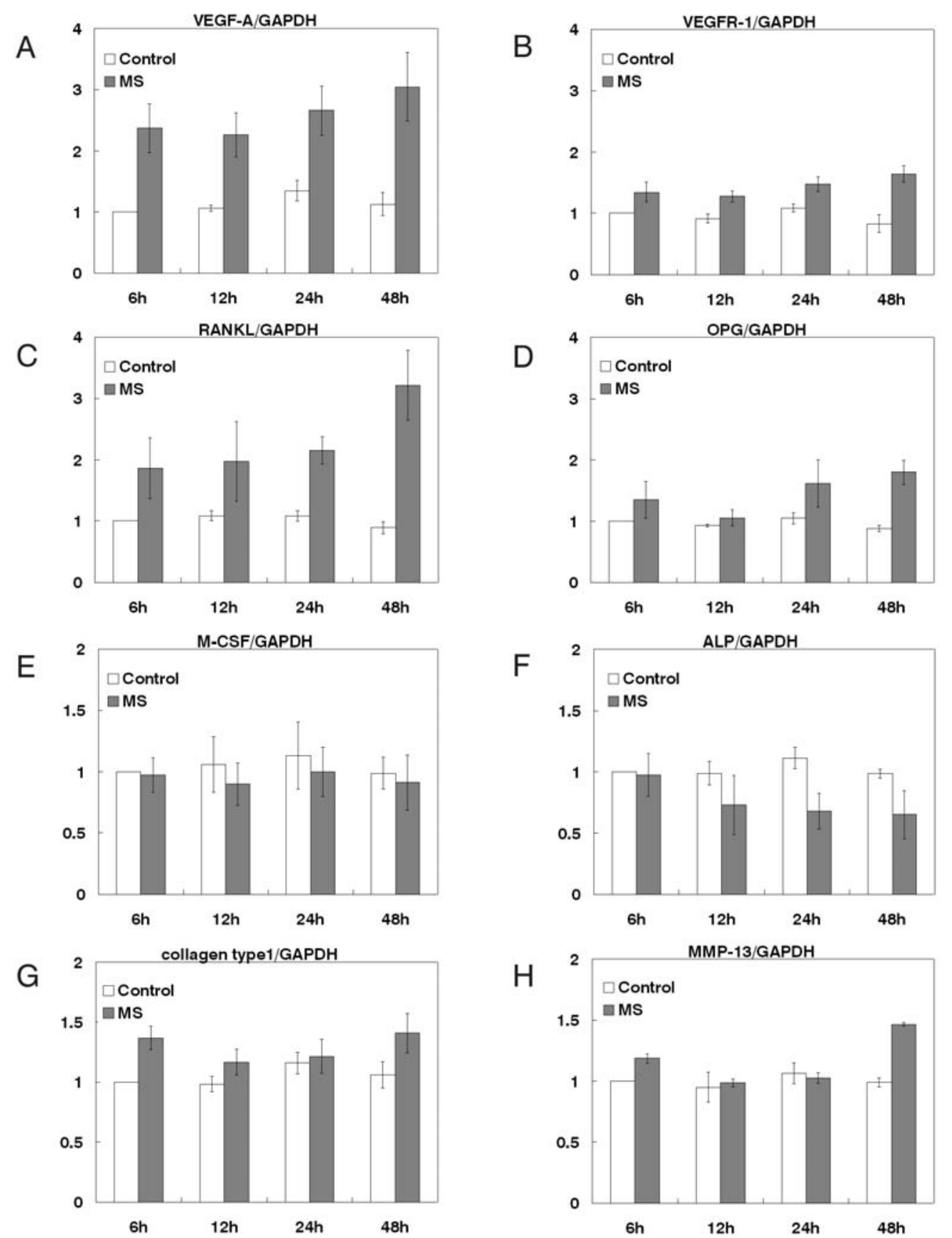

Figure 1. The effect of mechanical stress on mRNA expression of VEGF-A, VEGFR-1, RANKL, OPG, M-CSF, ALP, collagen type I and MMP-13. (A) VEGF-A mRNA expression increased time-dependently from $6 \mathrm{~h}$, and resulted in a 2.7-fold increase at $48 \mathrm{~h}$. (B) VEGFR-1 mRNA expression increased slightly at 6,12 and $24 \mathrm{~h}$, and resulted in a 2.0-fold increase at $48 \mathrm{~h}$. (C) RANKL mRNA expression increased time-dependently from $6 \mathrm{~h}$, and resulted in a 3.6 -fold increase at $48 \mathrm{~h}$. (D) OPG mRNA expression increased at 24 and $48 \mathrm{~h}$, and resulted in a 2.0 -fold increase at $48 \mathrm{~h}$. (E) M-CSF mRNA expression was unchanged at the 6,12, 24 and $48 \mathrm{~h}$ time points. (F) ALP mRNA expression decreased time-dependently, and resulted in a 0.65 -fold decrease at $48 \mathrm{~h}$. (G) Collagen type I mRNA expression remained unchanged. (H) MMP-13 mRNA expression resulted in a 1.5-fold increase at $48 \mathrm{~h}$ only. Results are shown as the means \pm SD $(\mathrm{n}=4)$. The control group at $6 \mathrm{~h}$ is defined as the standard $(=1)$. Control, control group; MS, mechanical stress group.

The protein concentration of M-CSF in the two groups increased time-dependently. M-CSF protein concentration in the mechanical stress group was reduced compared with the control group at 12, 24 and $48 \mathrm{~h}$ (Fig. 2B).

Neutralizing effect of anti-VEGF antibody on mRNA expression. VEGF-A mRNA expression in the mechanical stress group remained unchanged at 6 and $12 \mathrm{~h}$, but increased at 24 and $48 \mathrm{~h}$ compared with the control group (Fig. 3A). VEGFR-1 mRNA expression in the two groups remained unchanged at all time points (Fig. 3B). RANKL mRNA expression was unchanged at $6 \mathrm{~h}$, but increased at 12, 24 and $48 \mathrm{~h}$ (Fig. 3C). OPG mRNA expression remained unchanged at 6 and $12 \mathrm{~h}$ and slightly increased at 24 and $48 \mathrm{~h}$ (Fig. 3D). Treatment with anti-VEGF antibody reduced VEGF-A and RANKL mRNA expression by 0.53 - and 0.56 -fold compared with the non-mechanical stress group. VEGFR-1 mRNA expression was completely suppressed by the effect of the anti-VEGF antibody compared with the non-mechanical stress group. Neutralizing VEGF did not affect OPG mRNA 
A

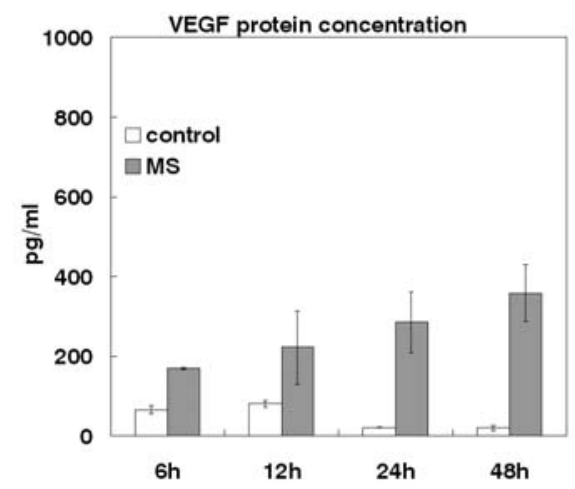

B

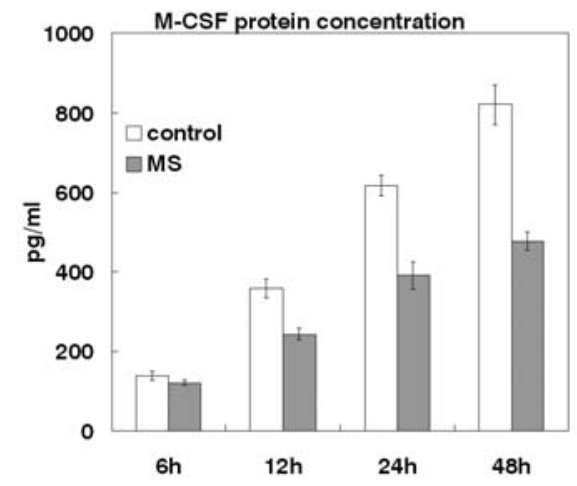

Figure 2. Effect of mechanical stress on the protein concentration of VEGF and M-CSF. (A) VEGF protein concentration in the mechanical stress group increased time-dependently, showing significant differences compared with the control group at 6, 12, 24 and 48 h, respectively. (B) M-CSF protein concentration in the two groups increased time-dependently, and was lower in the mechanical stress group than in the control group at 12,24 and $48 \mathrm{~h}$. The means and standard deviations of the VEGF and M-CSF protein concentration are shown ( $\mathrm{n}=4)$. Control, control group; MS, mechanical stress group.

expression under mechanical stress. M-CSF mRNA expression remained unchanged at all time points (Fig. 3E). ALP mRNA expression decreased time-dependently (Fig. 3F). Collagen type I and MMP-13 mRNA expression remained unchanged at all time points (Fig. $3 \mathrm{G}$ and $\mathrm{H}$ ). Neutralizing VEGF did not affect M-CSF, ALP and collagen type I mRNA expression under mechanical stress. MMP-13 mRNA expression was partially inhibited by the effect of anti-VEGF antibody compared with the non-mechanical stress group.

\section{Discussion}

It has been reported that VEGF is detected in periodontal tissues during experimental tooth movement, and that the local injection of VEGF enhances the number of osteoclasts and increases the rate of tooth movement $(29,30)$. The effect of anti-VEGF polyclonal antibody markedly decreased the number of osteoclasts and suppressed the amount of tooth movement and the relapse of moved teeth (31). Osteoblast activation requires cell-to-cell association between osteoblasts (RANKL) and osteoclasts (RANK) (32). It has been reported that osteoblasts may up-regulate VEGF expression in response to mechanical stress through the SA channel (23). Thus, we examined the effect of anti-VEGF antibody on the VEGF-A, VEGFR, RANKL and M-CSF mRNA expression of osteoblasts under conditions of mechanical stress. The results suggest that osteoblastic MC3T3-E1 cells up-regulate VEGF/ VEGFR-1 as a reaction to mechanical stress. As VEGF supports the differentiation and migration of osteoclasts and osteoblasts $(9,10,17-19)$, the VEGF/VEGFR-1 autocrine pathway is thought to play an important role in bone resorption. A recent report suggested that the VEGF signalling pathway through the VEGFR-1 tyrosine kinase domain is implicated in osteoblast development (33). The VEGF/VEGFR-1 autocrine loop in osteoblasts may activate its function in response to mechanical stress.

Suppression of RANKL mRNA expression by neutralizing VEGF indicates that this expression is assisted by the VEGF/ VEGFR-1 autocrine pathway. However, this study shows that mechanical stress up-regulates RANKL mRNA expression despite the interception of VEGF/VEGFR-1. It was reported that angiotensin II type 1 receptor (AT1), a known mechano- receptor in cardiomyocytes, up-regulates RANKL mRNA expression to some extent in mechanically stressed osteoblasts (34). Such receptors of mechanical stimulation are also expected to control RANKL mRNA expression.

As OPG is the decoy receptor for RANKL and inhibits osteoclastogenesis, the bone resorption rate is controlled by the balance of RANKL and OPG $(5,6)$. OPG mRNA expression was slightly up-regulated, thereby delaying RANKL mRNA expression. It appears that this negative feedback suppressed RANKL overexpression in osteoblasts.

The protein concentration of M-CSF in the two groups increased time-dependently. However, the protein concentration of VEGF in the control group did not. These results may be due to the fact that osteoblasts express VEGF/ VEGFR-1 but not the M-CSF receptor c-Fms $(35,36)$. Since no significant difference was observed in M-CSF mRNA expression, the induction of osteoclast precursor cells was expected to be accelerated by VEGF acting as a substitute for M-CSF.

It has been reported that ALP probably withdraws inorganic pyrophosphate (PPi), known as the inhibition of bone mineralization (37). Extracellular phosphate concentration is expected to be necessary and sufficient to induce bone mineralization (38). In this study, ALP mRNA expression was time-dependently down-regulated by mechanical stress. The down-regulation of ALP expression may help in the promotion of bone resorption.

Bone matrix is composed of collagen type I and noncollagenous protein. Osteoblasts participate in bone formation by producing collagen type I (39). In this study, mechanical stress and neutralizing VEGF did not affect collagen type I mRNA expression. It has been reported that MMP-13 can degrade type I, II and III collagens (40), and can be utilized as a marker of osteoblastic differentiation (41). Acting in cooperation with cathepsin K and MMP-9 produced by osteoclasts, MMP-13 produced by osteoblast-lineage cells may engage in bone matrix degradation in the process of bone resorption. MMP-13 from osteoblasts plays an important role in the initiation and progress of bone resorption (42). MMP-13 mRNA expression was partially inhibited by the effect of antiVEGF antibody, raising the possibility that VEGF/VEGFR-1 partially supports MMP-13 mRNA expression. 

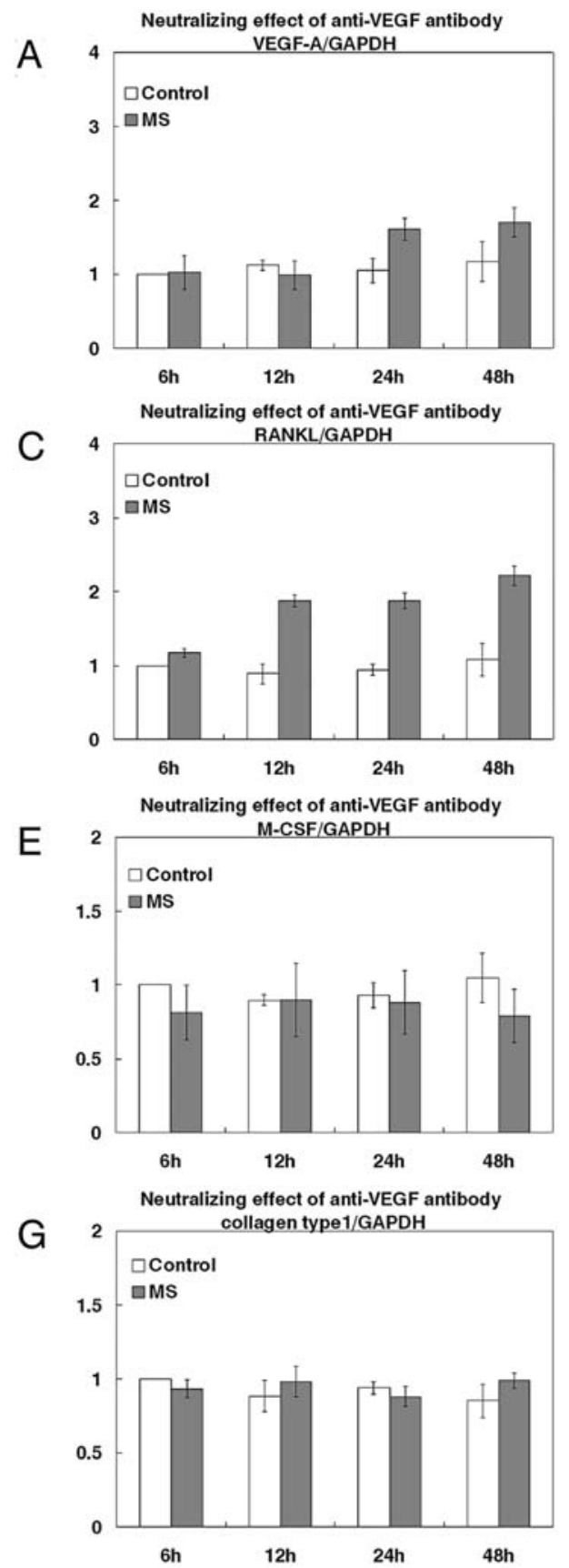
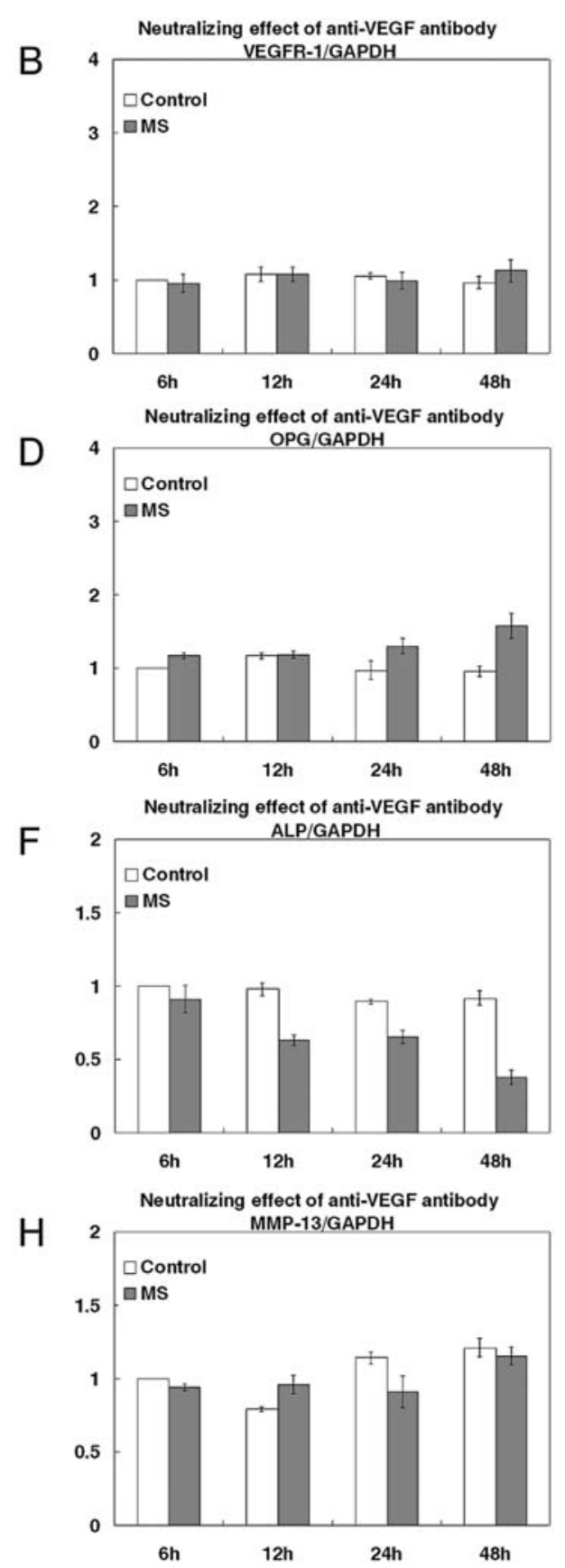

Figure 3. Neutralizing effect of anti-VEGF antibody on mRNA expression of VEGF-A, VEGFR-1, RANKL, OPG, M-CSF, ALP, collagen type I and MMP-13. VEGF-A mRNA expression was nearly equal to the control at 6 and $12 \mathrm{~h}$ and elevated at 24 and $48 \mathrm{~h}$. (A) VEGF-A mRNA expression resulted in a 1.5 -fold increase at $48 \mathrm{~h}$. (B) VEGFR-1 mRNA expression was equivalent to the control at 6,12,24 and $48 \mathrm{~h}$. (C) RANKL mRNA expression was nearly equal to the control at $6 \mathrm{~h}$ and elevated at 12,24 and $48 \mathrm{~h}$, and resulted in a 2.0-fold increase at $48 \mathrm{~h}$. (D) OPG mRNA expression increased slightly at 24 and $48 \mathrm{~h}$, and resulted in a 1.7-fold increase at $48 \mathrm{~h}$. (E) M-CSF mRNA expression remained unchanged at 6, 12, 24 and $48 \mathrm{~h}$. (F) ALP mRNA expression decreased time-dependently, and resulted in a 0.4 -fold decrease at $48 \mathrm{~h}$. (G and H) Collagen type I and MMP-13 mRNA expression was equivalent to control levels at $6,12,24$ and $48 \mathrm{~h}$. Results are shown as the means $\pm \mathrm{SD}(\mathrm{n}=4)$. The control group at $6 \mathrm{~h}$ is defined as the standard $(=1)$. Control, control group; MS, mechanical stress group.

In summary, since there are few reports on how the VEGF/VEGFR system functions and affects bone remodeling under mechanical stress in vitro, we aimed to investigate the VEGF/VEGFR system of osteoblasts with mechanical stress according to the flexercell tension system. We found that osteoblasts promote VEGF/VEGFR-1 expression and that the VEGF/VEGFR-1 autocrine pathway is involved in the reinforcement of RANKL expression in response to mechanical stress. Although no significant difference in M-CSF expression was observed, the induction of osteoclast precursor cells was apparently accelerated by VEGF acting as a substitute for
M-CSF. Therefore, mechanical stress up-regulates VEGF/ VEGFR-1 and RANKL expression, promotes osteoclast differentiation and induces bone resorption.

\section{Acknowledgements}

We are grateful to Dr N. Suzuki for technical advice and support. This study was supported in part by the Ministry of Education, Culture, Sports, Science and Technology of Japan [Kakenhi (B): grant no. 17390549 to J.I., Kakenhi (C): grant nos. 18592225 and 19592344 to Y.Y.]. 


\section{References}

1. Yoshida H, Hayashi S, Kunisada T, et al: The murine mutation osteopetrosis is in the coding region of the macrophage colony stimulating factor gene. Nature 345: 442-444, 1990.

2. Lacey DL, Timms E, Tan HL, Kelley MJ, et al: Osteoprotegerin ligand is a cytokine that regulates osteoclast differentiation and activation. Cell 93: 165-176, 1998 .

3. Udagawa N, Takahashi N, Jimi E, et al: Osteoblasts/stroma cells stimulate osteoclast activation through expression of osteoclast differentiation factor/RANKL but not macrophage colonystimulating factor: receptor activator of NF-kappa B ligand. Bone 25: 517-523, 1999.

4. Nakagawa N, Kinosaki M, Yamaguchi K, et al: RANK is the essential signaling receptor for osteoclast differentiation factor in osteoclastogenesis. Biochem Biophys Res Commun 253: 395-400, 1998

5. Udagawa N, Takahashi N, Yasuda H, et al: Osteoprotegerin produced by osteoblasts is an important regulator in osteoclast development and function. Endocrinology 141: 3478-3484, 2000.

6. Boyle WJ, Simonet WS and Lacey DL: Osteoclast differentiation and activation. Nature 423: 337-342, 2003.

7. Mochizuki A, Takami M, Kawawa T, et al: Identification and characterization of the precursors committed to osteoclasts induced by TNF-related activation-induced cytokine/receptor activator of NF-кB ligand. J Immunol 177: 4360-4368, 2006.

8. Leung DW, Cachianes G, Kuang WJ, Goeddel DV and Ferrara N: Vascular endothelial growth factor is a secreted angiogenic mitogen. Science 246: 1306-1309, 1989.

9. Niida S, Kaku M, Amano H, et al: Vascular endothelial growth factor can substitute for macrophage colony-stimulating factor in the support of osteoclastic bone resorption. J Exp Med 190: 293-298, 1999.

10. Nakagawa M, Kaneda T, Arakawa T, et al: Vascular endothelial growth factor (VEGF) directly enhances osteoclastic bone resorption and survival of mature osteoclasts. FEBS Lett 473: 161-164, 2000

11. Carmeliet P, Ferreira V, Breier G, et al: Abnormal blood vessel development and lethality in embryos lacking a single VEGF allele. Nature 380: 435-439, 1996.

12. Ferrara N, Carver-Moore K, Chen H, et al: Heterozygous embryonic lethality induced by targeted inactivation of the VEGF gene. Nature 380: 439-442, 1996.

13. Ogawa S, Oku A, Sawano A, Yamaguchi S, Yazaki Y and Shibuya M: A novel type of vascular endothelial growth factor, VEGF-E(NZ-7 VEGF), preferentially utilizes KDR/Flk-1 receptor and carries a potent mitotic activity without heparin-binding domain. J Biol Chem 273: 31273-31282, 1998.

14. Shibuya M: Structure and dual function of vascular endothelial growth factor receptor-1 (Flt-1). Int J Biochem Cell Biol 33 409-420, 2001.

15. Tombran-Tink $\mathrm{J}$ and Barnstable CJ: Osteoblasts and osteoclasts express PEDF, VEGF-A isoforms, and VEGF receptors: possible mediators of angiogenesis and matrix remodeling in the bone. Biochem Biophys Res Commun 316: 573-579, 2004.

16. Baron RE: Primer on the Metabolic Bone Diseases and Disorders of Mineral Metabolism. 3rd edition. Favus MJ (ed). LippincottRaven, New York, pp3-10, 1996.

17. Deckers MM, Karperien M, van der Bent C, Yamashita T, Papapoulos SE and Lowik CW: Expression of vascular endothelial growth factors and their receptors during osteoblast differentiation. Endocrinology 141: 1667-1674, 2000

18. Mayr-Wohlfart U, Waletenberger J, Hausser H, et al: Vascular endothelial growth factor stimulates chemotactic migration of primary human osteoblasts. Bone 30: 472-477, 2002.

19. Uchida S, Sakai A, Kudo H, et al: Vascular endothelial growth factor is expressed along with its receptors during the healing process of bone and bone marrow after drill-hole injury in rats. Bone 32: 491-501, 2003.

20. Sato K, Adachi T, Ueda D, Hojo M and Tomita Y: Measurement of local strain on cell membrane at initiation point of calcium signaling response to applied mechanical stimulus in osteoblastic cells. J Biomech 40: 1246-1255, 2007.
21. Jansen JH, Weyts FA, Westbroek I, et al: Stretch-induced phosphorylation of ERK1/2 depends on differentiation stage of osteoblasts. J Cell Biochem 93: 542-551, 2004.

22. Kim DW, Lee HJ, Karmin JA, et al: Mechanical loading differentially regulates membrane-bound and soluble RANKL availability in MC3T3-E1 cells. Ann NY Acad Sci 1068: 568-572, 2006.

23. Motokawa M, Kaku M, Tohma Y, et al: Effects of cyclic tensile forces on the expression of vascular endothelial growth factor (VEGF) and macrophage-colony stimulating factor (M-CSF) in murine osteoblastic MC3T3-E1 cells. J Dent Res 84: 422-427, 2005.

24. Holliday LS, Welgus HG, Fliszar CJ, Veith GM, Jeffrey JJ and Gluck SL: Initiation of osteoclast bone resorption by interstitial collagenase. J Biol Chem 272: 22053-22058, 1997.

25. Yang CM, Chien CS, Yao CC, Hsiao LD, Huang YC and Wu CB: Mechanical strain induces collagenase-3 (MMP-13) expression in MC3T3-E1 osteoblastic cells. J Biol Chem 279: 22158-22165, 2004.

26. Yoshimura Y, Kikuiri T, Deyama Y, Hasegawa T, Hatta M and Suzuki K: Hydrostatic pressure stimulates the fusion process in osteoclasts. Dent Jpn 40: 35-37, 2004.

27. Vande Geest JP, Di Mrtino ES and Vorp DA: An analysis of the complete strain field within Flexercell ${ }^{\mathrm{TM}}$ membranes. J Biomech 37: 1923-1928, 2004.

28. Suzuki N, Yoshimura Y, Deyama Y, Suzuki K and Kitagawa Y: Mechanical stress directly suppresses osteoclast differentiation in RAW264.7 cells. Int J Mol Med 21: 291-296, 2008.

29. Kaku M, Kohno S, Kawata T, et al: Effects of vascular endothelial growth factor on osteoclast induction during tooth movement in mice. J Dent Res 80: 1880-1883, 2001.

30. Kohno S, Kaku M, Tsutsui K, et al: Expression of vascular endothelial growth factor and the effects on bone remodeling during experimental tooth movement. J Dent Res 82: 177-182, 2003

31. Kohno S, Kaku M, Kawata T, et al: Neutralizing effects of an anti-vascular endothelial growth factor antibody on tooth movement. Angle Orthod 75: 797-804, 2005.

32. Jimi E, Nakamura I, Amano H, et al: Osteoclast function is activated by osteoblastic cells through a mechanism involving cell-to-cell contact. Endocrinology 137: 2187-2190, 1996.

33. Otomo H, Sakai A, Uchida S, et al: Flt-1 tyrosine kinase-deficient homozygous mice result in decreased trabecular bone volume with reduced osteogenic potential. Bone 40: 1494-1501, 2007.

34. Bandow K, Nishikawa Y, Ohnishi T, et al: Low-intensity pulsed ultrasound (LIPUS) induces RANKL, MCP-1, and MIP-1beta expression in osteoblasts through the angiotensin II type 1 receptor. J Cell Physiol 211: 392-398, 2007.

35. Weir EC, Horowitz MC, Baron R, Centrella M, Kacinski BM and Insogna KL: Macrophage colony-stimulating factor release and receptor expression in bone cells. J Bone Miner Res 8: 1507-1518, 1993.

36. Ninomiya K, Miyamoto $\mathrm{T}$, Imai $\mathrm{J}$, et al: Osteoclastic activity induces osteomodulin expression in osteoblasts. Biochem Biophys Res Commun 362: 460-466, 2007.

37. Oyajobi BO, Caswell AM and Russell RG: Transforming growth factor beta increases ecto-nucleoside triphosphate pyrophosphatase activity of human bone-derived cells. J Bone Miner Res 9: 99-109, 1994.

38. Murshed M, Harmey D, Millán JL, McKee MD and Karsenty G: Unique coexpression in osteoblasts of broadly expressed genes accounts for the spatial restriction of ECM mineralization to bone. Genes Dev 19: 1093-1104, 2005.

39. Sandberg M, Vuorio T, Hirvonen H, Alitalo $\mathrm{K}$ and Vuorio E: Enhanced expression of TGF-beta and c-fos mRNAs in the growth plates of developing human long bones. Development 102: 461-470, 1988.

40. Knauper V, Lopez-Otin C, Smith B, Knight G and Murphy G: Biochemical characterization of human collagenase-3. J Biol Chem 271: 1544-1550, 1996.

41. Fosang AJ, Last K, Knauper V, Murphy G and Neame PJ: Degradation of cartilage aggrecan by collagenase-3 (MMP-13). FEBS Lett 380: 17-20, 1996.

42. Nakamura H, Sato G, Hirata A and Yamamoto T: Immunolocalization of matrix metalloproteinase- 13 on bone surface under osteoclasts in rat tibia. Bone 34: 48-56, 2004. 